\title{
PUBLICIDAD IN GAME: EL MOVIMIENTO COCA-COLA
}

\author{
Estrella Martínez-Rodrigo: Universidad de Málaga (España) \\ Lourdes Sánchez Martín: Universidad de Granada (España)

\section{Introducción}

En la actualidad, el auge de los videojuegos entre el público adolescente y joven es notorio. Como señala Lamb et al, esta industria supone "el segundo segmento de más rápido crecimiento en el entretenimiento, después de Internet" ${ }^{1}$ y "un $68 \%$ de niños entre 7 y 13 juega habitualmente"2. Es sobre todo a partir de los 12 años cuando estos juegos se van consolidando según los intereses del adolescente.

La amplia participación y uso que los más jóvenes hacen de este tipo de juegos ha propiciado el interés por parte de las marcas y, más concretamente, de la publicidad. Así, diferentes compañías y agencias publicitarias han constatado las posibilidades que ofrecen los videojuegos para dar a conocer y difundir sus productos y marcas entre los más jóvenes. Además, la publicidad in game, presenta ciertas ventajas y ha producido cambios notables en la relación tradicional entre anunciantes y potenciales consumidores o receptores. Los jugadores pueden por primera vez interaccionar con un determinado producto o marca desempeñando un rol activo.

Si a este panorama sumamos además el auge de la red, la publicidad in game puede llegar a un gran número de usuarios de un modo rápido y eficaz y, además, como señala Suburana, "las características de este tipo de publicidad la convierten en un medio importante para segmentar mercados, conocer al cliente e incrementar las ventas"3.

A continuación se analizarán y detallarán las características de la publicidad in game, así como los diversos formatos, product placement, advertainment y advergaming, para a continuación analizar el caso de la plataforma El Movimiento Coca-Cola. Este mundo virtual ha logrado alcanzar a un millón de jóvenes y, al mismo tiempo, integra de forma coherente y exitosa las diferentes hibridaciones publicitarias.

\section{Nuevos formatos publicitarios}

El ámbito publicitario ha encontrado en nuevos formatos la posibilidad de innovar y afrontar la saturación publicitaria de sus receptores. De este modo, han surgido diferentes hibridaciones que pretenden aproximar a los receptores a los contenidos publicitarios de un modo novedoso para así captar su atención. Entre estos

\footnotetext{
${ }^{1}$ Lamb, C. W.; Hair, J. F. \& McDaniel, C. Fundamentos de marketing. México: International Thomson Editores. 2006. Pág. 5.

${ }^{2}$ Gil Juárez, A. \& Vilda Mombiela, T. Los videojuegos. Barcelona: Editorial UOC. 2007. Pág. 112.

${ }^{3}$ Subirana, B. \& Oliver, X. El despertar de la publicidad interactiva. Cuadernos del ebcenter. Center PwC \& IESE. 2006. Pág. 39.
} 
novedosos formatos destacan el product placement, advertising y advergaming. A continuación se detallarán las características de cada una de estas estrategias.

\subsection{Product Placement}

El product placement o brand placement hace referencia al emplazamiento del producto o marca. Aunque es comúnmente utilizado en el cine, radio y televisión, en la actualidad, esta herramienta de marketing se ha integrado también en el ámbito de los videojuegos. Como define Panda, el product placement es "la práctica de incluir el nombre, producto, embalaje, señalización u otro artículo de merchandising de una marca, en una película de cine, en televisión o en otros medios con el fin de incrementar la notoriedad y el reconocimiento inmediato de la marca en el punto de compra"4. No obstante, la aparición de cualquier marca o producto en un emplazamiento determinado se considerará product placement siempre y cuando exista una compensación económica por dicha presencia.

De este modo, los usuarios de videojuegos encuentran, mientras están en el escenario de juego, los contenidos publicitarios integrados en este entorno. En la mayor parte de las ocasiones, este emplazamiento se producto en los propios decorados del videojuego, en donde puede aparecer por ejemplo cartelería o letreros de la marca o el producto como elementos de una calle, un estadio o en el lugar concreto en donde discurre la acción.

\subsection{Advertainment}

El advertainment hace referencia, como define Martínez ${ }^{5}$, a "aquellos mensajes que resultan ser un híbrido entre publicidad y entretenimiento". Esta estrategia es definida como "una simbiosis perfecta entre publicidad y entretenimiento que tiene como principal objetivo atraer al público hacia los valores de la marca de forma atractiva y sugerente"6. El advertainment ha sido principalmente utilizado en la ficción audiovisual, aunque también existe un segundo grupo de este tipo de publicidad que se produce principalmente en los espacios virtuales de entretenimiento en donde la marca se fusiona con los contenidos del entorno online.

\subsection{Advergaming}

El advergaming hace referencia a la creación y uso de videojuegos con fines publicitarios, siempre y cuando el videojuego en cuestión sea creado y diseñado para la promoción de la marca. De este modo en estos videojuegos la marca o producto es parte esencial de la propia narrativa, incluso estableciéndose el producto como personaje u objeto a través del cual se desarrolla el propio juego. Por tanto, la presencia de la marca en el advergaming es muy superior a la que se

\footnotetext{
${ }^{4}$ Panda, T. K. Effectiveness of Product Placements in Indian Films and its effects on Brand Memory and Attitude with Special Reference to Hindi Films". The ICFAI Journal of Marketing Management (Agosto). 2004. Pág. 1.

${ }^{5}$ Martínez Sáez, J. “Branded content o advertainment. ¿Un nuevo escenario para la publicidad audiovisual?”, en Mínguez Arranz, N. y Villagra García, N.: La comunicación. Nuevos discursos y perspectivas. Sevilla: Edipo. 2003. Pág. 57.

6 Ramos, M. "Cuando la marca ofrece entretenimiento: aproximación al concepto de adver-tainment". Questiones Publicitarias, vol. I, nº 11, 2006. Pág. 39.
} 
produce por ejemplo en la herramienta product placement, en donde la presencia es aislada y corresponde a un momento y lugar concreto.

El origen del advergaming se remonta a los años 80, aunque se recurrió a ellos de manera muy esporádica. Sin embargo, en la actualidad, debido al creciente desarrollo y uso de Internet, el advergaming está encontrando en la red de redes un nuevo medio a través del cual aumentar su difusión y al mismo tiempo propiciar la interacción con los potenciales consumidores.

Dentro de esta estrategia publicitaria podemos encontrar diversos tipos de advergaming:

- Advergame: videojuegos aislados creados por la marca.

- Virtual World Advertising: mundo virtual no creado por la marca pero que, sin embargo, reserva un espacio determinado para el desarrollo y la presencia virtual de una marca. De este modo, el anunciante se integra en un mundo virtual ajeno y, por tanto, en la narrativa de la comunidad. Su presencia no se limita al emplazamiento, sino que además los usuarios pueden hacer uso de herramientas u objetos publicitarios dentro del mundo virtual.

- Adverworlds: mundo virtual creado por la propia marca. En este caso, la presencia de la marca es mayor que en los virtual world advertising, puesto que la comunidad en su conjunto ha sido creada por un anunciante y la presencia publicitaria es por tanto muy superior. En estas plataformas los usuarios pueden interaccionar en mayor medida con la marca e incluso utilizar más herramientas y elementos creados por ella.

Este tipo de hibridaciones publicitarias -product placement, advertainment $y$ advergaming- o publicidad in game, centradas en los videojuegos permiten afrontar la saturación publicitaria a la que se enfrenta el espectador y, al mismo tiempo, supone una evolución novedosa de la publicidad tradicional. Con los videojuegos, el receptor deja de actuar pasivamente para desarrollar un rol activo que le permite interaccionar con los distintos elementos publicitarios, personajes e incluso con otros usuarios.

Aunque estas hibridaciones se producen principalmente en los videojuegos tradicionales, entendiendo estos como aquellos juegos que el consumidor adquiere en cualquier establecimiento, en los últimos años también se han implementado en los videojuegos online. Internet, como señala Rodríguez et al ha supuesto "cambios en el entorno de los mercados electrónicos. A través de él, se constata cómo los internautas, muy informados y exigentes, muestran un gran interés por recibir tratamiento singular, desempeñar un rol diferente y más activo en su relación con la empresa, disfrutar de nuevas experiencias con el uso de las TIC y, en ocasiones, por rememorar situaciones y tiempos pasados"7.

A continuación se analizará un caso que manifiesta esta evolución de la publicidad tradicional y el asentimiento de la publicidad in game en España, el caso desarrollado por la marca Coca-Cola.

\footnotetext{
${ }^{7}$ Rodríguez Ardura, I.; Ammetller Montes, G. \& Pachecho Bernal, M. C. Nuevas ideas para los mercados electrónicos. Marketing... ¿posmoderno? MK Marketing+Ventas, № 220, Enero. 2007. Pág. 37.
} 


\section{El movimiento Coca-Cola}

El Movimiento Coca-Cola surgió en el año 2003. Se trata de un adverworlds centrado exclusivamente en Coca-Cola y creado por la empresa Bete-Byte. Para poder disfrutar de este mundo virtual, los usuarios deben descargar e instalar el programa que se ofrece en la propia página web de la marca. Tras su instalación, se puede acceder, previo registro, al adverworlds de Coca-Cola, así como a los diferentes advergames y el resto de elementos y contenidos que ofrece la comunidad y la marca.

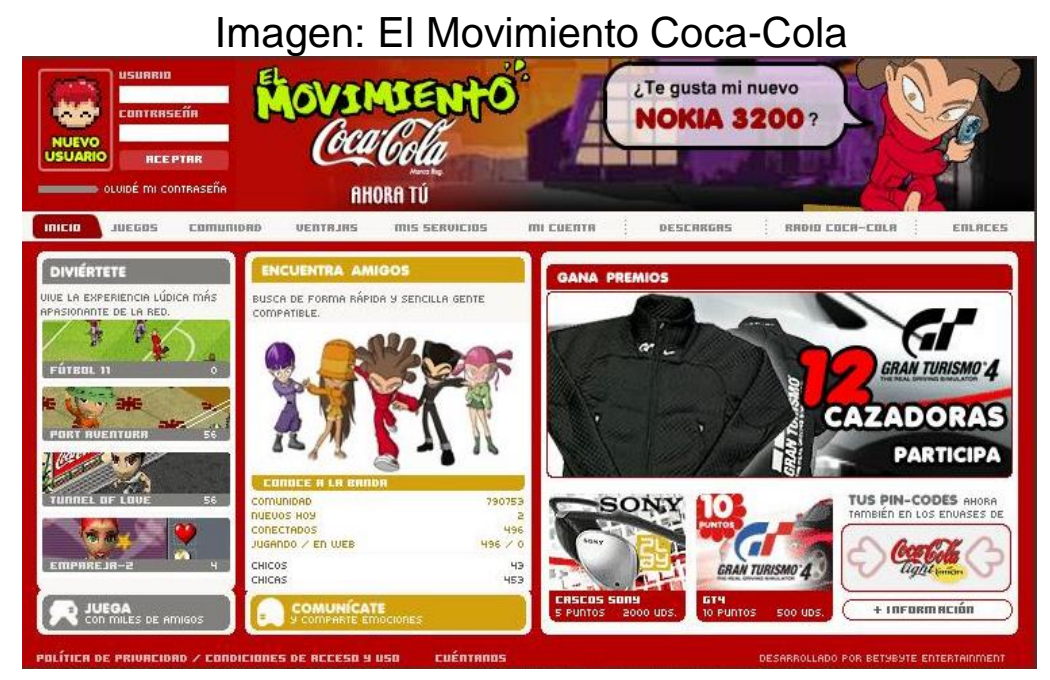

Como señala Caralt, "el Movimiento empezó de una forma muy sencilla: con tres juegos y había una especie de chat". Rápidamente, la marca constató la entrada de los más jóvenes a la plataforma y fue entonces cuando se planteó "llevar a cabo una mayor inversión en tiempo y en dinero para crear contenidos potentes y captar así la atención de toda esa gente joven"8. El gran número de jóvenes que atrajo la plataforma en sus primeros años provocó rápidamente su expansión que ha llegado en la actualidad hasta el millón de usuarios.

Los contenidos que ofrece la marca en El Movimiento Coca-Cola son numerosos y diversos, de modo que los usuarios pueden jugar a videojuegos con temáticas diversas, escuchar la radio, interactuar con otros usuarios, descargar contenidos 0 incluso optar a premios. Para acceder, los usuarios deben crear su avatar o alter ego virtual, personaje que los representará en la plataforma y ante el resto de usuarios. Para ello, pueden elegir la forma y el color de diversos elementos: ojos, pelo, vestimenta, etc. Una vez construido su personaje tienen acceso a la comunidad y pueden comenzar a jugar o a relacionarse con otros.

$$
\text { Imagen: Alter ego virtual }
$$

\footnotetext{
${ }^{8}$ Caralt, A. Crear marca en Internet. Del estar al ser. En: López Lita, R.; Fernández Beltrán, F. \& Durán Mañes, A. (Eds.). La comunicación local por Internet. IV Congreso de Comunicación Local (ComLoc). Castelló de la Plana: Publicacions de la Universitat Jaume I. 2005. Pág. 38.
} 


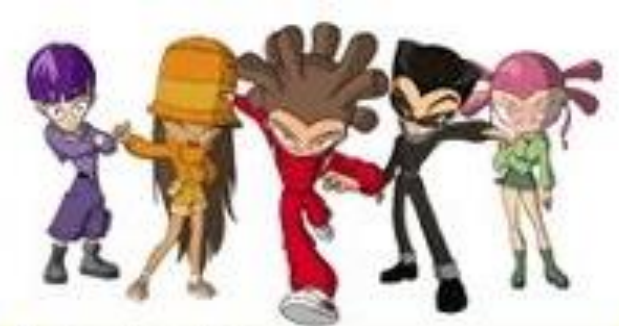

Fuente: El Movimiento Coca-Cola

Los advergames que ofrece la plataforma son cuatro que a continuación se detallan:

- Empareja-2: el juego crea dos equipos diferenciados con un máximo de cuatro chicas y cuatro chicos. La temática del juego consiste en ocho rondas de preguntas y respuestas que se realizan entre ambos equipos. Cada grupo debe valorar las respuestas del equipo contrario y, en función de las calificaciones obtenidas y la semejanza que se produzca en las respuestas de los jugadores, los chicos y chicas serán emparejados. En caso de que la similitud no sea suficiente, los usuarios pueden obtener la valoración que el equipo contrario ha realizado sobre sus respuestas.

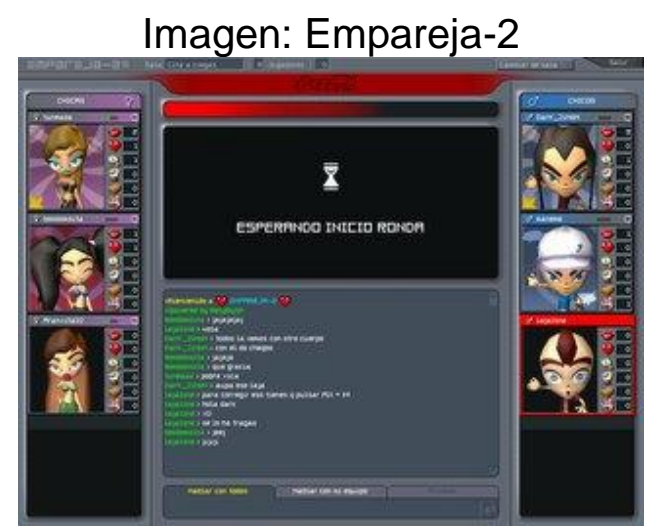

Fuente: El Movimiento Coca-Cola

- Tunnel of Love: el juego discurre por una ciudad virtual que el personaje puede recorrer libremente. A lo largo de su camino, el jugador se encontrará con personajes que le solicitan objetos. El objetivo del juego es entonces encontrar esos elementos antes que los contrincantes. Además, a lo largo de su búsqueda, el usuario puede interacción con otros jugadores que se encuentran también en la ciudad a través de su avatar personal. 


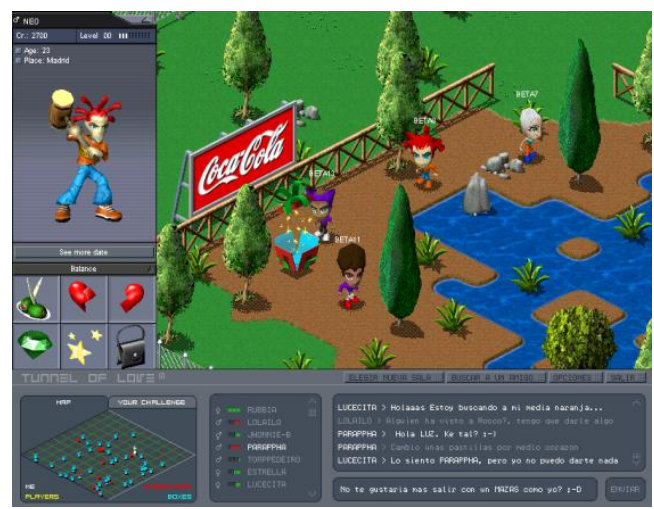

Fuente: El Movimiento Coca-Cola

- Fútbol 11: juego de estrategia cuya temática es el fútbol. Los usuarios deben planificar sus movimientos para conseguir ganar el partido al contrincante.

- Port Aventura: videojuego basado en el conocido parque de atracciones. El juego consiste en la superación de distintas pruebas en las que los usuarios deben lograr finalmente la caída libre más rápida de una atracción.

- Universal: juego en el que el usuario puede construir su casa y decorarla dentro del mundo virtual.

Además, los usuarios pueden acceder a una comunidad virtual en la que interactuar con el resto tanto de manera pública como de manera privada a través del chat general y de los mensajes privados. Al mismo tiempo, cada juego permite chatear, aunque públicamente de una manera más privada que la comunidad, entre los jugadores o miembros de los equipos.

Por otra parte, los usuarios tienen acceso a múltiples ventajas y otro tipo de contenidos. Como recoge Nicolás et al, "el contenido se divide en seis pestañas bajo los títulos: inicio, juegos, comunidad, ventajas, mis servicios, mi cuenta, nuevos usuarios, radio Coca-Cola y Enlaces" ${ }^{\prime}$. A través de la plataforma los jóvenes pueden canjear pincodes que se encuentras en los productos de Coca-Cola por diferentes regalos físicos, pero también regalos virtuales. Estos últimos se centran principalmente en en complementos y vestuario exclusivo para el avatar o en elementos decorativos para la construcción de la casa personal del avatar en el juego Universal.

El Movimiento Coca-Cola y los diversos elementos que lo constituyen manifiestna la implantación de diversas y variadas estrategias in game. Por una parte, la configuración de la plataforma y creación de un mundo virtual propia es un Adverworlds. Dentro de este adverworlds, podemos diferenciar los distintos advergames, elemento principal de la comunidad y el que supone el principal atractivo para los adolescentes y jóvenes. Además, dentro de cada advergame y,

\footnotetext{
${ }^{9}$ Nicolás Romera, C. \& Nicolás Ojeda, M. A. Identidades juveniles y discursos de marcas: la creación de imagen corporativa en los nuevos escenarios tecno-comunicativos. Global Media Journal, Vol. 2, Na 3, Primavera. 2005. http://gmje.mty.itesm.mx/articulos2/cesar_nicolas_ot04.html
} 
más específicamente, en el juego Tunnel of Love, Fútbol 11 o Universal, se encuentran diversos elementos decorativos que configuran, en el primer caso las calles del mundo virtual y del juego, en el caso de Fútbol 11, vallas publicitarias integradas que realizan publicidad sobre Coca-Cola y elementos decorativos para el hogar en Universal. Además, la comunidad de Coca-Cola pretende reportar entretenimiento a sus usuarios a través de los diversos contenidos que les ofrece. Por ello, podemos asegurar que el desarrollo de la estrategia de advertainment está también claramente presente. Como señala Ramos, El Movimiento Coca-Cola "pretende ser un lugar de encuentro para los jóvenes donde pueden hallar cualquier contenido bajo la forma de entretenimiento" 10 y lo cierto es que la marca ha logrado reportar ese entretenimiento a sus usuarios, como así manifiesta el enorme éxito alcanzado. Coca-Cola ha sabido realizar de manera coherente una integración total de su publicidad en la plataforma, recurriendo a diversos formatos e hibridaciones publicitarias. Como señala Rodríguez et al, los jóvenes encuentran en El Movimiento Coca-Cola "una mezcla de información, diversión y entretenimiento. Asimismo, el cliente desarrolla un papel tan activo en el proceso de comunicación que llega a adoptar funciones que venían siendo específicas del vendedor: es él quien decide a qué información comercial exponerse, de qué modo se le presentarán la oferta y los contenidos, etc."11.

Coca-Cola genera así experiencias lúdicas en los jóvenes y, por tanto positivas, que provocarán que estos asocien esas experiencias con la marca. Así, la estrategia de Coca-Cola consiste en "dar sentido a la experiencia de sus destinatarios, a través de la integración del discurso publicitario en el plano de la cotidianeidad"12.

\section{Conclusiones}

El Movimiento Coca-Cola es un claro ejemplo de las nuevas posibilidades publicitarias que depara Internet y las hibridaciones en los próximos años. La marca ha sabido aprovechar, por una parte el desarrollo y auge de Internet y, por otra parte, el interés de los jóvenes por los videojuegos. Teniendo en cuenta estos aspectos, El Movimiento Coca-Cola ha logrado integrar de manera conjunta y coherente un gran número de hibridaciones y estrategias publicitarias -adverworlds, advergames, advertainment, product placement- y, al mismo tiempo, aproximarse a un target especialmente joven, logrando su participación activa e implicación con la marca.

En los próximos años, seguramente podremos ver como otras marcas reproducen el caso que nos ocupa creando nuevas plataformas y comunidades que conecten entre sí a su público y, al mismo tiempo, establezcan una conexión entre cada usuario y la marca en un entorno online. Por ello, resulta interesante profundizar en las nuevas posibilidades publicitarias que ofrece la red, dado que este entorno determinará en el futuro el nuevo modo de hacer publicidad en donde el usuario asumirá un rol activo.

\footnotetext{
${ }^{10}$ Ramos, M. Op. Cit. Pág. 46

${ }^{11}$ Rodríguez. Op. Cit. Pág. 34

12 San Nicolás Romera, C. Branding, subvertising y mercados de la experiencia. Revista CIDOB d'afers internacionals, №66-67, 165-181. 2004. Pág. 166.
} 


\section{Referencias}

CARALT, A. Crear marca en Internet. Del estar al ser. En: López Lita, R.; Fernández Beltrán, F. \& Durán Mañes, A. (Eds.). La comunicación local por Internet. IV Congreso de Comunicación Local (ComLoc). Castelló de la Plana: Publicacions de la Universitat Jaume I. 2005.

GIL JUÁREZ, A. \& VILDA MOMBIELA, T. Los videojuegos. Barcelona: Editorial UOC. 2007.

LAMB, C. W.; HAIR, J. F. \& MCDANIEL, C. Fundamentos de marketing. México: International Thomson Editores. 2006.

MARTÍNEZ SÁEZ, J. "Branded content o advertainment. ¿Un nuevo escenario para la publicidad audiovisual?", en Mínguez Arranz, N. y Villagra García, N. La comunicación. Nuevos discursos y perspectivas. Sevilla. Edipo. 2003. pp. 5762.

NICOLÁS ROMERA, C. \& NICOLÁS OJEDA, M. A. Identidades juveniles y discursos de marcas: la creación de imagen corporativa en los nuevos escenarios tecnocomunicativos. Global Media Journal, Vol. 2, № http://gmje.mty.itesm.mx/articulos2/cesar nicolas ot04.html

PANDA, T. K. Effectiveness of Product Placements in Indian Films and its effects on Brand Memory and Attitude with Special Reference to Hindi Films. The ICFAI Journal of Marketing Management (Agosto), 2004, pp. 42-56.

RAMOS, M. "Cuando la marca ofrece entretenimiento: aproximación al concepto de advertainment". Questiones Publicitarias, vol. I, № 11, 2006, pp. 33-49.

RODRÍGUEZ ARDURA, I.; AMMETLLER MONTES, G. \& PACHECHO BERNAL, M. C. Nuevas ideas para los mercados electrónicos. Marketing... ¿posmoderno? MK Marketing+Ventas, № 220, Enero, 2007, pp. 32-37. http://www.consum.cat/documentacio/8842.pdf

SAN NICOLÁS ROMERA, C. Branding, subvertising y mercados de la experiencia. Revista CIDOB d'afers internacionals, № 66-67, 2004, pp. 165-181. http://dialnet.unirioja.es/servlet/articulo?codigo $=1010816$

SUBIRANA, B. \& OLIVER, X. El despertar de la publicidad interactiva. Cuadernos del ebcenter. Center PwC \& IESE. 2006.

http://www.iese.edu/research/pdfs/ESTUDIO-51.pdf 